\title{
EXPERIENCES OF AFRICAN INTERNATIONAL STUDENTS IN A SOUTH AFRICAN UNIVERSITY - A QUALITATIVE STUDY
}

\author{
M. Kasese-Hara* \\ Department of Psychology \\ https://orcid.org/0000-0001-5692-4956
}

\section{J. I. Mugambi*}

Counselling Psychologist

https://orcid.org/0000-0002-9470-7941

*University of the Witwatersrand

Johannesburg, South Africa

\section{ABSTRACT}

South Africa has in latter decades embraced the growing trend of internationalization in higher education leading to greater international mobility of staff and students. Compared to other countries in most of the sub-Saharan Africa region, South Africa has a larger capacity to meet the tertiary needs of students within the region. An increasing number of international students has implications for their academic success, adaptation and wellbeing once in their host country. The current study explored the lived experiences of international students in a South African university, from 5 other African countries. The study adopted a qualitative design, using semi-structured indepth interviews and open-ended questions. Nine mainly postgraduate students (4 males and 5 females) were recruited using convenient and snowball sampling methods. Data were analysed using thematic content analysis and revealed 5 themes namely "Internationalisation", "experiencing the unforeseen", "access", "social support" and "structural support", with several sub-themes emerging from these. A resulting framework shows "empowerment", "alienation" and "adaptation" as over-arching themes in experiencing the phenomenon of being an African foreign student in South Africa.

Keywords: socio-cultural transition, student mobility and coping, international students, intercultural adaptation, African students, push and pull factors.

\section{INTRODUCTION}

The main aim of this study was to explore the daily lived experiences of African international students at a South African university, located in Gauteng province.

A growing trend in academia is that of international mobility of both staff and students leading to a global shift towards international education (Altbach and Teichler 2001). Reasons for why students go to other countries include access to higher education, quality of education, 
seeking internationally recognised qualifications, and international work opportunities (Chien and Kot 2012; McGregor 2014). Within the African continent, South Africa is regarded as an advanced knowledge hub that attracts a large number of African International students (DHET 2017). Compared to the United Kingdom and the Unites States, South Africa has pull factors such as better education opportunities and cheaper fees that makes it a destination of choice for students from other African countries (McGregor 2014). There are also benefits from internationalisation of higher education for host countries. International students contribute to host country economies and to the tertiary education system through tutoring, working in local companies and even starting own businesses (Brown and Brown 2013). International students are also a source of revenue through visa fees remittances, tuition fees, skills impartation, medical insurance payments, accommodation, entertainment etc. (Aloyo 2009; DHET 2017).

However, countries must balance these benefits against local higher education interests and objectives (DHET 2017).

International students in South Africa, especially those from other African countries, have been known to struggle with immigration policy controls, which are viewed as discriminatory with stringent conditions that must be adhered to (Ramphele, Crush, and McDonald 1999). For instance, being excluded from certain employment opportunities within the university reserved for local students, premium international fees, lengthy application processes and repatriation costs that need to be paid in advance are decried as punitive (Ramphele et al. 1999; Naidoo 2015). All of these conditions are deemed to foster exclusion rather than inclusion and negatively impact on the socio-emotional functioning of students (Naidoo 2015).

Social support structures are critical in the adaptation of international students to the challenges brought by the cross-cultural transition (Contreras-Aguirre and Gonzalez 2017). However, access to culturally sensitive support structures may be limited for African international students or may be deemed as Eurocentric (Constantine et al. 2005). Research suggests that foreign university students have to find ways to cope with adjustment struggles, the social environment, and the academic contexts through various support structures (Smith and Khawaja 2011; Naidoo 2015; Sennett et al. 2003). Compared to international counterparts from North America and Europe, many students from African countries in South Africa do not come well-funded from their countries of origin (Dominguez-Whitehead and Sing 2015). Additional challenges include meeting recurrent expenses like food, transport and accommodation and may require financial support (Naidoo 2015). Research also shows that students depend on kinship networks, for money and coping with loneliness and social stress, especially if they reside in the same country (Wilcox, Winn, and Fyvie-Gauld 2005; Constantine et al. 2005). 
Building social relationships produces a link between adjustment and social support which determines how well international students adapt into the host university (Leong 2015). However, these social relationships do not necessarily involve host populations (Leong 2015) as international students may find it easier to build social networks with those from their own nationality and culture. These relationships act as protective factors in their daily lived experiences (Contreras-Aguirre and Gonzalez 2017; Hoehne 2012). Social networks are thus critical because they contribute to a student's sense of identity, well-being, agency and capabilities (Madhavan and Landau 2011; Muthuki 2014).

Acculturation refers to the process of intercultural adaptation, which according to Ward, Bochner, and Furnham (2001) is broadly divided into two categories namely, the psychological and sociocultural components of adaptation to a new cultural environment. While psychological adaptation is situated in a stress and coping framework, sociocultural adaptation is situated within a cultural learning framework (Ward et al. 2001; Zhou et al. 2008). This model is an elaborate integration of the key elements of other models of intercultural adaptation, and views transitions across cultures as a significant life event involving adaptive change (Zhou et al. 2008). According to this model, the individual's response to cultural transition will involve their affect, behaviour and cognition in acquiring stress-management and the desired social skills, which subsequently lead them to psychological adjustment and socio-cultural adaptation. The acquisition of stress coping strategies and culturally relevant social skills is the major task the individual needs to master in the process of cultural transition. This model incorporates a wide range of variables at the individual, situational (e.g., reasons for migration, amount of life change, social support etc.) and the societal levels (e.g., social, political, economic factors in the host country and country of origin). The model is deemed as offering a comprehensive explanation for cross-cultural transition and is used as the basis for discussion in the current article. This article attempts to incorporate aspects of this theory particularly as regards the factors that aid coping and culturally relevant skills that play a facilitative role in socio-cultural adaptation.

\section{RESEARCH QUESTION}

A lot of research on migrants in South Africa exists but is mainly from the perspective of xenophobia (e.g., Adjai and Lazaridis 2014; Chiweshe 2016; Crush 2001; Harris 2002; Landau, Ramjathan-Keogh, and Singh 2005; Neocosmos 2008). In this regard, most of the research has foregrounded xenophobia which is only one aspect of migrants' lived experiences. By keeping the aim broad and exploring daily lived experiences, the current research has opened up discussions through open-ended questions about migrant students' daily lives. Ramphele et al. 
(1999) acknowledge that international students as a subsection of migrants are an integral part of internationally recognised universities, and any benefits to be gained from them must be recognised. The rationale for this research is propelled by this need to understand the migrant student as a socially embedded individual in a foreign environment and uncover a broader picture of their daily experiences which at present is scarce.

To direct the study, the research question asked was "What are the daily lived experiences of African international students at a Gauteng-based university?" The question allowed for an exploration of experiences of students generally without being directional towards either positive or negative experiences, but rather encompassing all experiences. The purpose of this study was therefore, to seek an in-depth understanding of the experience of being an international student in South Africa from the perspective of African students from neighbouring countries. The study aimed to explore the topic and expand on the somewhat limited academic knowledge that currently exists on the actual experiences of foreign students in South Africa, by exploring the topic broadly and expecting to confirm some of the information encountered in the literature review, but also adding new insights through first hand experiences of the sampled individuals.

At the onset, it is important to define the term "lived experience". Van Manen (2016) describes "lived experience" as first-hand accounts that require sensitivity and understanding of a person's unique situation. Given the increased trends in student mobility globally, it is crucial to not only investigate and uncover stories, but to also extend this towards opportunities for changes in pedagogic settings (Pithouse-Morgan et al. 2012).

\section{METHODS}

\section{Research design}

The main aim of this study was to explore the daily lived experiences of African international students at a South African university, located in Gauteng province. The study was located within a qualitative research design and was grounded in an interpretative social constructivism paradigm, meaning that the findings would be grounded in how the individuals make meaning of their experiences socially and historically (Creswell 2007). The research study was an exploration of the lived experiences of nine African international students at a Gauteng based university. An epistemological standpoint was taken where realities were uncovered collaboratively through interactions between the researcher and the participants.

\section{Sampling}

Purposive and snowball sampling techniques (Creswell 2007) were used to select a sample of 
foreign students originally from African countries, studying at a university located Johannesburg, South Africa. A total of nine participants were interviewed between June and November 2017 including five female and four male students (see Table 1). The selected sample was diverse in that there were students from 5 African countries included, who all grew up in very different geo-political and social contexts, leading to a richly diverse set of experiences prior to coming to South Africa, and shaping their experience and perception of their host country as international students. Eight out of the nine participants were postgraduate students between the ages of 25-43 years, and one was an Honours ( $4^{\text {th }}$ year, pre-Masters $)$ level student aged 26 years. This study targeted postgraduate students, as they were also likely to bring a more mature, and deeper perspective to their lived experiences.

\section{Data collection procedure}

A semi-structured interview schedule containing six open-ended questions was used to collect data. Open-ended questions to encourage conversation and in-depth data extraction (Creswell 2007). Most interviews took place in the researcher's office at the university campus, one in a quiet coffee shop and another at the participant's home. Interviews took approximately one hour, were audio recorded and transcribed verbatim. Voluntary participation, informed consent and confidentiality through pseudonyms were ensured.

Trustworthiness was ensured by addressing t the credibility, dependability, transferability and confirmability of the study (Korstjens and Moser 2018). The primary researcher also kept a self-reflexive journal of her experiences, values and assumptions in relation to the research process (Korstjens and Moser 2018). The study was approved by the University's Ethics committee.

\section{Data analysis}

As the research was grounded in an interpretivist approach, it was critical that data analysis allow for open-ended deeper realities to emerge. Thematic content analysis was chosen to allow for flexibility in extracting rich and detailed accounts of information that is theoretically and methodologically sound (Clarke and Braun 2013a). Clarke and Braun's (2013a) six step Thematic Analysis was adopted as a guide to identify, analyze and report themes across the data set; and content, semantic and latent features of the data were teased out and analyzed for meaning (Clarke and Braun 2013b). Researcher triangulation was applied by the author and coauthor working closely to interrogate the themes.

An inductive approach was used to analyse the data and arrive at a framework for understanding the experience of being an African international student in South Africa. 
Table 1: Participants Demographics

\begin{tabular}{|c|l|c|c|l|l|l|}
\hline & $\begin{array}{l}\text { Participants } \\
\text { (Pseudonyms) }\end{array}$ & Gender & Age & Nationality & Study Program in RSA & $\begin{array}{c}\text { Age of Arrival } \\
\text { in South Africa } \\
\text { (no. of years in } \\
\text { South Africa) }\end{array}$ \\
\hline 1 & Masimba & M & 34 & Zimbabwe & PhD - Sociology & $29(5$ years $)$ \\
\hline 2 & Shamiso & F & 33 & Zimbabwe & Masters - Psychology & $20(13$ years) \\
\hline 3 & Gift & M & 30 & Zimbabwe & PhD - Migration studies & $28(2$ years $)$ \\
\hline 4 & Jacinta & F & 31 & Kenya & PhD - Development studies & $12(19$ years $)$ \\
\hline 5 & Naomi & F & 25 & Kenya & Masters - Migration studies & $20(5$ years $)$ \\
\hline 6 & Olufemi & M & 35 & Nigeria & PhD - Development studies & $28(7$ years $)$ \\
\hline 7 & Abiola & F & 43 & Nigeria & Masters - Drama Therapy & $36(7$ years $)$ \\
\hline 8 & Eleanor & F & 26 & Uganda & $\begin{array}{l}\text { Honours - Human } \\
\text { Resources Management }\end{array}$ & 23 (3 years $)$ \\
\hline 9 & Paul & M & 25 & Rwanda & $\begin{array}{l}\text { Bachelors - Clinical Medical } \\
\text { Practice }\end{array}$ & 7 (18 years $)$ \\
\hline
\end{tabular}

Table 2: Summary of themes and subthemes

\begin{tabular}{|c|c|c|c|}
\hline $\begin{array}{c}\text { Overarching } \\
\text { Themes }\end{array}$ & Themes & Sub-Themes & Participants cited \\
\hline \multirow{6}{*}{ EMPOWERMENT } & \multirow{3}{*}{ Internationalisation } & Politics of internationalisation & - $\quad[\mathrm{P} 1, \mathrm{P} 2, \mathrm{P} 7]$ \\
\hline & & Pull and push factors & - $\quad[\mathrm{P} 3, \mathrm{P} 2, \mathrm{P} 6, \mathrm{P} 4, \mathrm{P} 1, \mathrm{P} 9]$ \\
\hline & & Studying in a cosmopolitan city & - $\quad[\mathrm{P} 2, \mathrm{P} 8, \mathrm{P} 1, \mathrm{P} 5, \mathrm{P} 8, \mathrm{P} 6, \mathrm{P} 4]$ \\
\hline & \multirow{3}{*}{$\begin{array}{l}\text { Experiencing the } \\
\text { unforeseen }\end{array}$} & Culture shock & - $\quad[\mathrm{P} 8, \mathrm{P} 6, \mathrm{P} 2, \mathrm{P} 7]$ \\
\hline & & Daunting bureaucratic processes & - $\quad[\mathrm{P} 5, \mathrm{P} 8, \mathrm{P} 3, \mathrm{P} 6, \mathrm{P} 2]$ \\
\hline & & Racism & - $\quad[\mathrm{P} 2, \mathrm{P} 3, \mathrm{P} 4, \mathrm{P} 7, \mathrm{P} 8, \mathrm{P} 9]$ \\
\hline \multirow{6}{*}{ ALIENATION } & \multirow{3}{*}{ Access } & $\begin{array}{l}\text { Funding opportunities \& } \\
\text { international fees }\end{array}$ & - $\quad[\mathrm{P} 1, \mathrm{P} 2, \mathrm{P} 3, \mathrm{P} 4, \mathrm{P} 5, \mathrm{P} 6]$ \\
\hline & & Access to work and income & - $\quad[\mathrm{P} 1, \mathrm{P} 2, \mathrm{P} 4, \mathrm{P} 5, \mathrm{P} 6, \mathrm{P} 8]$ \\
\hline & & Accessing healthcare services & - $\quad[\mathrm{P} 1, \mathrm{P} 3, \mathrm{P} 4, \mathrm{P} 5, \mathrm{P} 6]$ \\
\hline & \multirow{4}{*}{ Social support } & Loneliness and need for support & - $\quad[\mathrm{P} 1, \mathrm{P} 3, \mathrm{P} 4, \mathrm{P} 6, \mathrm{P} 7, \mathrm{P} 8, \mathrm{P} 9]$ \\
\hline & & Support from academic staff & - $[\mathrm{P} 1, \mathrm{P} 4, \mathrm{P} 6]$ \\
\hline & & Student-to-student support & - $\quad[\mathrm{P} 1, \mathrm{P} 2, \mathrm{P} 5, \mathrm{P} 6, \mathrm{P} 8]$ \\
\hline \multirow{3}{*}{ ADAPTATION } & & Country and Kinship connections & - $\quad[\mathrm{P} 1, \mathrm{P} 3, \mathrm{P} 4, \mathrm{P} 6, \mathrm{P} 7, \mathrm{P} 8]$ \\
\hline & \multirow[t]{2}{*}{ Structural support } & $\begin{array}{l}\text { Orientation and the role of the } \\
\text { International Office }\end{array}$ & - $\quad[\mathrm{P} 1, \mathrm{P} 5, \mathrm{P} 6, \mathrm{P} 8]$ \\
\hline & & Sports, clubs \& faith & - $\quad[\mathrm{P} 1, \mathrm{P} 3, \mathrm{P} 4, \mathrm{P} 6, \mathrm{P} 7, \mathrm{P} 8, \mathrm{P} 9]$ \\
\hline
\end{tabular}

\section{RESULTS}

\section{Introduction}

Five main themes emerged out of the lived experiences of African international students, namely "Internationalisation", "experiencing the unforeseen", "access", "social support" and "structural support"; and several sub-themes were generated from these themes (see Table 2). Further analysis resulting in a framework for understanding the experience of African international students in South Africa yielded 3 overarching themes namely, "empowerment", 
"alienation" and "adaptation".

"Empowerment" describes participants' ability to gain access to quality higher education and better opportunities, and ability to thrive in that environment, facilitated by policies and practices in their host environment mainly through "internationalisation" and "access". "Alienation" refers to the sense of loneliness, not belonging or ill-treatment resulting from the experience of being a foreigner and a student at an institution of higher learning in South Africa. These experiences and perceptions are initiated and exacerbated by anti-foreigner immigration policies and stringent visa processes, culture shock and the racialised culture in the social and learning environments in South Africa. "Adaptation" refers to participants' ability to discover ways of coping, survival and learning, mainly through social support and structural support.

Due to space constraints the results reported herein are partial results from the main study due to the wealth of data collected.

\section{Internationalisation}

Internationalisation has emerged as a result of globalisation and although these terms tend to be used synonymously, internationalisation refers to the cross-border movement and activities of peoples, cultures and systems (DHET 2017), while globalisation is considered as the expansion of social processes to depict worldwide trends and creates interconnectivity among countries around the globe (Teichler 2004). With the advent of internationalisation, universities in South Africa have become accessible to students from other countries, and especially from within the African continent for various reasons. The subthemes under internationalisation included "Politics of internationalisation", "Push and pull factors" and "Studying in a cosmopolitan city". This theme only has links with 2 over-arching themes, namely "empowerment" and "experiencing the unforeseen".

\section{Politics of internationalization}

Participants spoke about the existing tensions in the transformation agenda, particularly, how being a foreign African student carried the potential to either advantage or disadvantage one when applying for university admission

Masimba: "Issues of transformation, yeah ... I think it's now closing opportunities for international students, they are now trying to go South African first ...."

Shamiso: "If they wanted diversity and I was the only [laughs] Black (a foreigner) it might have put me at an advantage, but I'm not sure, I haven't felt like it."

\section{Pull and push factors}

Participants were attracted by the availability of subsidies, better quality higher education, the 
favourable global standing of South African universities etc. They also cited reasons for wanting to move from their home countries:

Gift: "Before I applied, I had a chance to look at the official website something that actually attracted me to come and study ... it is one of the best institutions globally."

Masimba: "So I decided to move from Zimbabwe to this place in 2015, just because, you know, of a lot of things associated with economic crisis in Zimbabwe."

Paul: "I should rather say that Rwanda was a very political ... environment so you come here as a refugee."

\section{Studying in a cosmopolitan city}

Studying in Johannesburg exposes participants to a large, well developed city with a diversity of peoples and cultures, advanced infrastructure and other offerings:

Shamiso: "I just fell in love with the place, like it's a beautiful country ... I find the place very fancy!" [Laughs]

Eleanor: "Accessibility is fast, everything is fast, the roads are proper I have forgotten all the horrible potholes from my country ... the roads, the fast life, everything is quick."

Masimba: "You hardly feel foreign, because this - it is more like a cosmopolitan institution where you have different people from different backgrounds. Everything is different, everyone is different."

However, there were also negative experiences such as crime reported by Naomi.

\section{Experiencing the unforeseen}

Three sub-themes emerged under this theme namely, "Culture shock", "Daunting bureaucratic processes" and "encountering racism". This theme was connected to two over-arching themes, namely "empowerment" and "alienation" (Figure 1).

\section{Culture shock}

Participants experienced notable differences in social norms, values and beliefs from the way of life in their country of origin.

Eleanor: "I have never been to a more (relaxed) and liberal country like South Africa .... Unlike where I come from (Uganda), where my president says that you shouldn't wear short skirts, no gays or lesbians. You come here ... and you see people wearing bum shorts, and you are wow ... [Laughs] ... how do you do that!" 
Figure 1: Framework of experiencing being a foreign student in South Africa

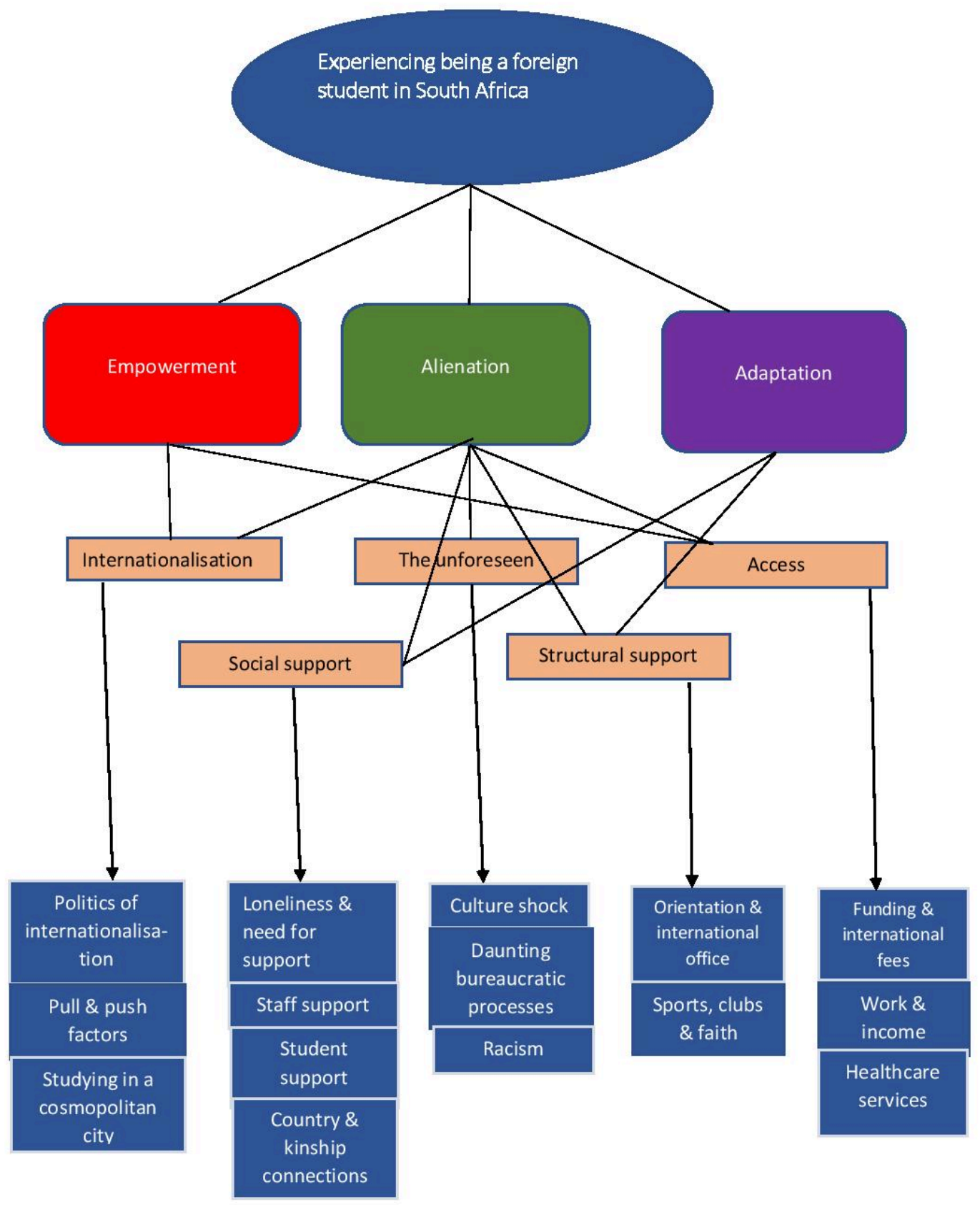

Figure 1: Framework of experiencing begin a foreign student in South Africa 
Culture shock was also in the form of an inability to identify with own family members who were already living in the host country, or differences in culturally appropriate interactions across age and status, or having to racially profile themselves.

Shamiso: "Growing (up) in Zimbabwe as a Black person, it's not implanted in your mind that someone could actually look down on you because you got a different skin colour."

Seekings (2008) asserts that a racial profiled culture exists amongst post-apartheid South Africans which permeates society, which required an adjustment in their social interactions and identity.

\section{Daunting bureaucratic processes}

The paperwork and bureaucracy required to obtain a study permit is regarded as one of the most traumatic experiences of being a foreign student in South Africa (Da Silva 2016). Participants spoke openly about the challenges of gaining entry as international students, including having to obtain a medical aid certificate, and SAQA approval for their previous academic qualifications which meant additional expenses.

Naomi: "I think a lot of us international students were actually struggling just in terms of visas and that kind of administration that really just made our experience here in South Africa quite unbearable."

Olufemi: "You have to send your qualifications to the SAQA [South African Qualifications Authority] board ... they just increased the amount from R860 to R1,010 .... What is the purpose of the international fee?"

\section{Encountering ethnicity and racism}

For some participants having White classmates and lecturers was a new experience which even affected some of their ability to interact freely in the classroom. This topic also elicited some discomfort during interviews for some participants as observed through nervous laughter.

Gift: "There was a lot of excitement that was associated with it, at one point, probably I was even afraid to participate. What do I say in front of these people?"

Eleanor: "It was so hectic, it was so overwhelming, and even the classes, you know, where I am from, we do not have Indian and White lecturers."

Participants spoke about varied experiences in academic and social spaces, both with people of their own skin colour and others. Participants expressed helplessness and feeling misunderstood, not knowing how to interact with both Black and White students. The experience of xenophobia 
by Africans in South Africa has been a common occurrence in recent decades (Tella 2016), and this study confirms that xenophobia is not restricted to low income townships and inner city shopping complexes alone, but is experienced by foreign students in a university context as well. Abiola for instance, felt that he did not fit in with either white or black students.

Abiola: "To them I was a Black person, but to the Black I had things that the White people would have ... if you relate too much to the White people, you are identifying with the oppressors - you are classified as one of them."

Within the classroom or academic contexts in the university, there were accounts of overt racialized encounters between different races as expressed by Eleanor in this example.

Eleanor: "And I'm wondering why are these two students fighting and I go there to try and calm them down and a Black girl is like, 'Don't even tell us to keep quiet, this boy is racist. You don't even know what he said when you walked in. He was saying 'why is it that a Black tutor is the one who is in here today?" So it was a bit of a strong issue."

Interactions with staff and fellow students were much more complex than to be attributed to race only. One participant found that white and Indian students where more approachable than local black students, while one felt that the only white students she could relate to where nonSouth African European white students. While participants overall felt that interactions with teaching staff were largely positive regardless of race, they encountered cryptic comments it could only be attributed to the pervasive racialised environment.

Jacinta: "One of the lecturers at the college where I lecture ..., when I told him I'm doing my $\mathrm{PhD}$, then he says 'oh, so you're not South African, are you?' So there's always these things people say attached to certain things that maybe because you're doing $\mathrm{PhD}$ and you're Black you might not be a South African - you must be from elsewhere and I think for me, this (is) the racial aspect."

\section{Access}

Internationalisation of higher education has led to universities opening up access to students beyond their borders (Sehoole 2011). However, real access is more than just opening up admission to international students, it should rather be a much broader concept better qualified by students' lived experiences (Chikoko et al. 2013). Despite the positive statistical increase in admission, new challenges of inequalities arise in trying to service the different student populations (Ilie and Rose, 2016). Participants expressed concern that as African international students their unique needs were somewhat unacknowledged by the institution after admission. "Access" as a theme was also linked to 2 over-arching themes namely, "empowerment" and 
"alienation" (see Figure 1). In particular, participants experienced empowerment in the domains of accessing funding, healthcare, and in accessing work and income, and experienced alienation to a lesser extent in these domains. Alienation was also experienced through restrictive fees for international students.

\section{Funding opportunities and international fees}

For many aspiring African students, South Africa is a preferred destination to North Africa, Europe and North America, for quality higher education due to its competitive fees (Mda 2010; Rouhani 2007; Sehoole 2011) and access to funding opportunities. Seven out of nine participants were able to access funding through the university, particularly on the basis of academic merit.

Shamiso: "I like the fact that there's a Post Graduate Merit Award at [Gauteng university], as long as you meet this standard, your marks are this good."

Nevertheless, participants felt that access to funding opportunities was limited and restricted and was predominantly for local students which made them feel excluded. Participants also complained about having to pay higher (international) fees than local students. Participants' lived experiences were tainted not only by limited access to funding but also a perceived lack of sympathy from the university. This added extra pressure for international students including, escalating debt as well as stress and anxiety.

Olufemi: "The funny (thing) is that the school does not understand and they do not want to know, they just want you off their system."

\section{Access to work and income}

As a means of countering the challenge of finances, participants talked about being vigilant in looking for opportunities within the university such as funding and work opportunities. Opportunities available were mostly part time, through lecturers, or as part of training in some of the departments within the university. This enabled them to gain experience, make money and supplement their subsistence.

Jacinta: "I do remember a time at [university name] when I was doing my masters. when I saw an advert [in a] certain department had advertised for research assistant and they (paid) R25 000 towards your fees, so I just went in and I was like, I'm on, and I helped them to do the fieldwork and at least it helps to pay my fees." (P4). 
Research suggests that international students can make a contribution to the local economy, higher education contexts and globalization (Brown and Brown 2013; Rouhani 2007). Not all participants had the same positive experiences in terms of access to job opportunities. For instance, Shamiso (from Zimbabwe) shared her frustration on being excluded from getting paid as a non-South African intern.

Shamiso: "The fact that next year I'm going to be working in a government hospital, my colleagues are getting thousands of Rands and I'm getting nothing by virtue of being [claps to emphasise] a non-South African .... Why am I not getting the money? Because I'm not South African - so what are you saying? It's okay to exploit me? It's okay for me to work for free because I'm not South African?" (P2).

\section{Access to health care services}

Access to health care is also noted as an area of concern for international students. One of the stipulated requirements for international students is medical cover. Participants spoke about the mandatory medical aid was insufficient. However, this was a source of frustration as the prescribed medical aid provider only provided limited access to health care services.

Gift: "Usually as foreign students, even before you apply for study permits, it is a requirement that you must have a 12-month medical cover ..., (but) not all hospitals and clinics accept [university] medical aids .... You feel like you're secured because you have a medical aid then you visit a hospital and they tell you that we don't accept this one." (P3).

\section{Social support}

Two over-arching themes were associated with "social support" namely "alienation" and "adaptation" (See Figure 1). While social support in itself is an adaptive phenomenon, the participants' narratives clearly show as seen in the "loneliness and need for psycho-social support" sub-theme, that a void existed in their host learning institution leaving them lonely and in need of psycho-social support, and this is an "alienating" experience.

\section{Loneliness and the need for psycho-social support}

Participants expressed loneliness due to being far from home. In addition, the loneliness was compounded by the academic stress:

Olufemi: “I didn't have a lot of friends. I wasn't introduced to a lot of people out here. It was basically myself, my books, and my room. So I still had to face some of those psychological issues." (P6). 
Participants expressed a lack of awareness amongst (foreign) students about the availability of psychosocial support services for students.

Abiola: "Maybe counselling would have helped. ... but there wasn't ... a proper structure to say ... this is where you should go If you're feeling so overwhelmed and especially if you have not schooled in South Africa before, where I don't know the systems."

Therefore, there seemed to be a gap in the university system either in communicating or familiarising the students with the support structures.

\section{Support from academic staff}

In order to cope with the demands of their new academic environment, international students also reached out and received support from lecturers and supervisors. Participants expressed gratitude for the compassion and support given by academic staff.

Masimba: "I got massive support from my lecturers, even when I was doing my masters. One of my lecturers, she paid for my accommodation."

Participants acknowledged the facilitative role played by their lecturers and supervisors in helping them access opportunities to earn money through tutoring work etc. Lecturers and supervisors also provided mentorship and emotional support.

Jacinta: "My supervisor ... she's just one of those incredible people ... She really is always available and always motivating, there was no time that she (didn't) put an effort into my work ...."

\section{Student-to-student support}

Participants were also drawn to friendships with and received support from other students. This study revealed a wider and more mixed student social support network that was a blend of international and local students.

Eleanor: "... and then she asked me where are you from and I said that I am from Uganda, because they easily know accents as we all don't sound the same. There she said I'm from Zim (and also international) and we have been close friends since then." (P8).

Naomi is the only participant who reported that her support did not primarily come from other international students. And she attributed this to international students having many struggles of their own. She also reasoned that South African students could not really grasp the challenges of being an international student 


\section{Country and kinship connections}

International students also initiated support amongst themselves via country and kinship associations. Inclining towards organisations from their own countries helped them to find a connection with "home" away from home.

Masimba: "We had a community of Zimbabweans, who were also open to interact with (us), and I remember I had friends from Nigeria, Cameroon, DRC, so it was easy to mix and integrate."

Of particular importance were both national and regional associations for example, the Ugandan association, East African Society and the West African Association. Participants also expressed feeling an affiliation with international students from other African countries. Furthermore, all nine participants were vocal about the importance of support from family or kinship relations, whether near or far. Family, whether local or abroad was seen as an instrumental source of emotional, physical and financial support. Having extended family residing in the country helped with resolving challenges with a lot more ease. Kinship ties were thus considered as protective factors in moderating the emotional, social, academic and financial challenges of being a foreign student.

Gift: My brother is here and I've got fellow countrymen from Zimbabwe, so usually when I am physically or financially challenged, those are some of the people whom I am free to approach. Like since we are from the same country, no language barrier, no cultural barrier."

Abiola: "I had a very supportive family, like I said, every day I would come back and tell my husband when I had a bad day ...."

\section{Structural support}

Although orientation and the international office should by nature be associated with student empowerment, participants saw the international office as largely redundant, and spoke about orientation only in light of the negative repercussions of being late for it due to delays in obtaining study permits. Participating in campus sports, joining clubs and practicing their faith helped participants to adapt to their new environment.

\section{Orientation and the role of the international office}

The international office is a key university structure aimed at providing the necessary support to international students. However, participants were hesitant to speak about the international office. They reported that the international office did not have the competency or awareness of 
their unique needs as foreign students. It was seen as an unhelpful "white elephant". The only significant service that the international office provided was perceived as issuing letters for study visas.

Naomi: "The international office is useless, apart from giving that clearance certificate in the beginning of the year they provide no form of support for international students. We really do not have that structured support that you expect the university to provide."

The inconvenience of missing orientation due to delays in the arduous visa processing can be devastating and may cause students to suffer numerous inconveniences in settling into the university.

Eleanor: "It was my first time in South Africa. I ... missed orientation ... I had come late, you know, so now I (did) not know (where to find) classes. I used to come to school and sit under the stairs and just wonder and cry and wish that I had gone back, you know, because I knew no one."

Eleanor had arrived late due to delays in obtaining the study visa and had also missed orientation. As a result, she struggled with settling in and adjusting to the academic environment. Naidoo (2015) suggests that orientation is an important aspect for new students, and more so, international students, because it contributes to faster adaptation and active participation within the university.

\section{Sports, Clubs and Faith}

Participants expressed a desire to be acknowledged and to extend their social interactions within different student social spaces and joining clubs or going to church helped to expand their social networks.

Gift: “... despite all our differences, when it comes to sports you play together as a team. We support together and ... it coheres, you know. Life is easier and that is how you make friends as well."

The positive influence of faith in mitigating stress and enhancing social relationships was evident in the interviews. Participants also acknowledged God and drew on support networks within religious contexts.

Jacinta: "I do feel that ... God has come through in certain things ... And I remember ..., being in the Christian organisation ... you meet so many students where another student ... might help you to ... get accommodation or to stay with them and so forth." (P4). 
Masimba: "Weekends, Sundays, I go to church. Being from a foreign country, I think it shapes your focus, you become more focused." (P1).

\section{DISCUSSION}

\section{Empowerment}

The results of this study draw us closer to understanding areas that may be empowering to African international students in SA in the domains of social and academic life which need to be encouraged and strengthened to enhance the quality of life experienced by foreign students. For this to occur there needs to be less ambiguity in the policy and conversations about diversity and inclusion as it relates to foreign students from neighbouring African countries.

Research by Darby, (2015) reveals that push and pull factors play an important role in growing student mobility. From the current study, it is clear that international students benefit from being in a large and well-developed city with diverse cultures, advanced infrastructure, accessibility to bursaries, and better-quality higher education. Participants moved from their home countries due to economic crises, political problems, or a lack of quality higher education in their home countries. Pull factors included the favourable global standing, availability of subsidies, and affordable, diverse and better-quality higher education in South Africa. This supports other findings that universities in South Africa are considered to be advanced and wellequipped adding to their appeal as a study destination (Sehoole 2011).

Participants saw the move as an opportunity to move away from the economic, educational or political adversity of their countries towards a more attractive environment in South Africa. The decline of university standards in other African countries has been shown to be a push factor in student mobility (Altbach and Teichler 2001), same as the economic woes and political instability in their home countries. And the tendency towards student mobility increases in times of economic, educational and political crises in African countries (Mdepa and Tshiwula 2012).

\section{Alienation}

Despite the funding opportunities, inflated international fees remains a huge financial challenge for African international students in SA. This state of affairs which is perceived as unfair by foreign students from the continent is condoned by the Department of Higher Education (SA) which allows for a differentiated approach towards tuition fees (DHET 2017), granting universities the leeway for additional sources of revenue including charging international fees.

It is well documented that foreign students face many hardships in South Africa. The interviews reveal that international students faced challenges including culture shock, racism, 
restricted employment opportunities, stringent immigration policies, and difficulties accessing healthcare etc. Participants reported a blend of tensions arising from the transformation agenda of South Africa involving advantages and disadvantages encountered in the process of applying for university admission. And while being black may have put them at an "advantage" (due to the pro-black national transformation agenda), participants felt disadvantaged because "South Africans are selected first". The current study reveals that African international students struggled to gain entry into the country and experienced difficulties with the visa process, which rolled over into other problems such as missing orientation and registration deadlines at the university, altogether resulting into some nightmarish settling-in experiences. Consistent with the literature, this study shows that adjusting to a new context can be anxiety provoking and stressful (Araiza and Kutugata 2013). International students described arriving into the host country as a "difficult period", due to among other things, encountering different social norms and beliefs, new culturally appropriate ways of interacting across age and status, and having to racially define oneself (a new experience for students coming from African countries where race is not an issue).

Orientation is a once-off event and the opportunity to attend, once missed (due in this case to lengthy visa processes or other reasons) may not be regained; it must also precede registration and so missing orientation leads to further complications. This led to students feeling alone and unsupported and added to the stress of being a student in a foreign country. South African universities must therefore, pay particular attention to the impact that visa processing delays have on student arrival, orientation and timely registration for their academic programmes. They should prioritise such students and pick up on them at the earliest opportunity to avoid dire academic and psycho-social consequences.

\section{Adaptation}

The current study begins to uncover relationships, structures and services which help African international students adapt to an otherwise alienating and potentially disempowering experience. Support systems already in place in the sampled university (notably one of the top 5 nationally) are not sufficient and need to be strengthened in order to render the required support.

The current study demonstrates that international students coped with social stress, loneliness and other challenges in their host country by leaning on support from their lecturers, supervisors, other students (mostly international), and relatives. They also attempted to expand and enhance their social circles and relationships through sports, clubs and faith-based activities. These structures of support are important facilitators of international students' 
transition into a new cultural environment (Contreras-Aguirre and Gonzalez 2017) and ought to be strengthened and supported.

According to Ward et al. (2001), two sets of factors determine the process and outcome of cross-cultural transition when people move into a new cultural environment. These include societal level variables, comprising aspects of the society of origin and the society of settlement, as well as individual level factors, comprising characteristics of both the person and the situation. Numerous factors come into play to shape one's cross-cultural transition in the form of life changes and intercultural contact with people in the host country (Zhou et al. 2008). A number of these factors are highlighted in the current study. At the societal level for instance, globalization and internationalization of higher education in South Africa and the consequent reaching out to an international pool of applicants have contributed to it being their choice for studies While push factors in their country of origin have also come to the fore. At the individual level in line with Furnham (2019), results showed that certain characteristics of individual students played a role in their adapting to their new learning environment for example "training and experience". Participants were able to gain access to part-time work as tutors or research assistants while studying, and as such could use their learning, whether formal or informal to aid their cultural transition.

Ward et al.'s (2001) postulation that the experience of cultural stress in the host country would eventually prompt the individual to adopt stress coping strategies and culture-specific skills is evident in the participants' narratives. These coping strategies and skills involve affective, behavioural and cognitive responses which ultimately lead to psychological and socio-cultural adaptation to the host culture. Participants shared a process of journeying through the initial difficulties and "culture shock", efforts to adapt to and learn strategies to cope by exploring and reaching out to support networks, and finally reaching a place of acceptance and functional settlement into their new learning environment. Clearly, there are individual differences in this process, and further research can explore the specific individual differences that determine differing outcomes.

\section{CONCLUSION}

The topic covered herein is seemingly well researched, but not much from a South African perspective; the weighted focus of local research on xenophobia, though a critical topic in its own right, does not allow for the full realm of the experiential phenomenon of being an international student in SA to emerge. The study reported herein highlights nuances of personal experiences of individuals who have left their own countries in pursuit of a quality education in a prestigious institution of higher learning in the city of Johannesburg, which is seen as the 
epicentre of globalization and advancement in the region. They do not only carry monetary value to the local economy through paying tuition fees, visa fees, living expenses etc., but also bring intellectual and critical thinking abilities that are often used within their universities in teaching, research as well as clinical settings. And yet, from their narrated experiences, at some level these foreign students experience the same marginalization as any other foreigner - from the arduous and even punitive immigration processes to settling-in hardships precipitated by poor, weak or non-existent support systems for international students; and alienating social interactions with local black and white students. A vicious circle of alienation is often created, especially when foreign students have arrived late which often begins with delays in visa obtaining procedures.

The current study provides highlights into areas of empowerment, alienation and adaptation experienced by African international students via the domains of "internationalisation", "experiencing the unforeseen", "access", "social support" and "structural support". Future research is required to enhance our understandings of how existing structures and systems can be developed and strengthened to better accommodate and support this valuable group of budding scholars and professionals who are academic visitors to South African universities.

\section{REFERENCES}

Adjai, C. and G. Lazaridis. 2014. "People, state and civic responses to immigration, xenophobia and racism in the new South Africa." Journal of International Migration and Integration 15(2): 237 255.

Aloyo, N. O. 2009. "The economic impact of international students on South Africa." Doctoral dissertation, University of Johannesburg.

Altbach, P. G. and U. Teichler. 2001. "Internationalization and exchanges in a globalized university." Journal of Studies in International Education 5(1): 5-25.

Araiza, M. J. and A. Kutugata. 2013. "Understanding stress in international students of higher education in a Mexican private university." Procedia-Social and Behavioral Sciences 106: 3184-3194.

Brown, J. and L. Brown. 2013. "The international student sojourn, identity conflict and threats to wellbeing." British Journal of Guidance \& Counselling 41(4): 395-413.

Chien, C. L. and F. C. Kot. 2012. "New Patterns in Student Mobility in the Southern Africa Development Community." UIS Information bulletin No.7. United Nations Educational, Scientific and Cultural Organization (UNESCO).

Chikoko, V., D. Pillay, K. J. Pithouse-Morgan, P. Morojele, and I. Naicker. 2013. "What access? Lived experiences of international post-graduate students from Africa studying in a South African university." Journal of Social Sciences 37(2): 167-177.

Chiweshe, M. K. 2016. "Social positionality and Xenophobia: The case of rugby player Tendai Mtawarira." South Africa. Journal of Pan African Studies 9(7): 132+.

Clarke, V. and V. Braun. 2013a. Successful qualitative research: A practical guide for beginners. Sage.

Clarke, V. and V. Braun. 2013b. "Teaching thematic analysis: Overcoming challenges and developing strategies for effective learning." The Psychologist 26(2): 120-123. 
Constantine, M. G., G. M. Anderson, L. A. Berkel, L. D. Caldwell, and S. O. Utsey. 2005. "Examining the cultural adjustment experiences of African international college students: A qualitative analysis." Journal of Counselling Psychology 52(1): 57.

Contreras-Aguirre, H. C. and E. Gonzalez. 2017. "Experiences of International Female Students in U.S. Graduate Programs." College Student Journal 51(1): 33-46.

Creswell, J. W. 2007. Qualitative inquiry and research method: Choosing among five approaches. Sage Publications.

Crush, J. 2001. "The dark side of democracy: Migration, xenophobia and human rights in South Africa." International Migration 38(6) Special Issue 2: 103-133. https://onlinelibrary.wiley.com/ doi/abs/10.1111/1468-2435.00145.

Darby, M. G. 2015. "Understanding Why International Student Applicants Choose a Public Four-year Institution." Doctoral dissertation, California State University - San Bernadino (CSUSB). CSUSB digital archive. https://scholarworks.lib.csusb.edu/etd/132/.

Da Silva, D. 2016. "How many hoops must African students jump through to study in South Africa?" The Daily Fox February 2016. http://www.thedailyvox.co.za/how-many-hoops-must-africanstudents-jump-through-to-study-in-south-africa/.

Department of Higher Education and Training 2017. Draft Policy Framework for the Internationalisation of Higher Education in South Africa. Pretoria: (C) Department of Higher Education and Training. http://www.dhet.gov.za.

DHET see Department of Higher Education and Training.

Dominguez-Whitehead, Y. and N. Sing. 2015. "International students in the South African higher education system: A review of pressing challenges." South African Journal of Higher Education 29(4): 77-95.

Furnham, A. 2019. "Culture Shock: A review of the literature for practitioners." Psychology 10: 18321855. doi: $10.4236 /$ psych.2019.1013119.

Harris, B. 2002. "Xenophobia: A new pathology for a new South Africa?" In Psychopathology and Social Prejudice, ed. D. Hook and G. Eagle, 169-184. Cape Town: University of Cape Town Press.

Hoehne, D. 2012. "The impact of informal social networks on integration - A case study of migrant learners at Jules High School in central Johannesburg." Masters Dissertation. University of the Witwatersrand, Johannesburg. http://www.wits.ac.za/library/(Electronic Theses and Dissertations).

Ilie, S. and P. Rose. 2016. "Is equal access to higher education in South Asia and sub-Saharan Africa achievable by 2030." Higher Education 72(4): 435-455.

Korstjens, I. and A. Moser. 2018. "Series: Practical guidance to qualitative research. Part 4: trustworthiness and publishing". European Journal of General Practice 24(1): 120-124.

Landau, L. B., K. Ramjathan-Keogh and G. Singh. 2005. Xenophobia in South Africa and problems related to it. Johannesburg: Forced Migration Studies Programme, University of the Witwatersrand.

Leong, P. 2015. "Coming to America: Assessing the patterns of acculturation, friendship formation, and the academic experiences of international students at a US college." Journal of International Students 5(4): 459. https://jistudents.org/2015-volume-54/.

Madhavan, S. and L. B. Landau. 2011. "Bridges to nowhere: Hosts, migrants, and the chimera of social capital in three African cities." Population and Development Review 37(3): 473-497.

McGregor, K. 2014. "Major survey of international student in South Africa." World University News September, 6333. http://www.universityworldnews.com/article.php?story=20140905134914811.

Mda, T. V. 2010. Home away from home? African international students in South African universities. Human Sciences Research Council, South Africa.

Mdepa, W. and L. Tshiwula. 2012. "Student diversity in South African higher education." Widening Participation and Lifelong Learning 13(1): 19-33. 
Muthuki, J. M. 2014. "Religion as mechanism of adaptation for immigrants: The case of African migrant students in a South African tertiary institution.” Journal of Social Development in Africa 29(1): 109.

Naidoo, D. 2015. "The experiences of in/exclusion and marginalization of international students at a private higher education institution." Doctoral dissertation.

Neocosmos, M. 2008. "The Politics of Fear and the Fear of Politics: Reflections on Xenophobic Violence in South Africa." Journal of Asian and African Studies 43(6). DOI:10.1177/0021909608096655.

Pithouse-Morgan, K., P. Morojele, D. Pillay, I. Naicker, V. Chikoko, R. Ramkelawan, and R. Rajpal. 2012. "'The air is hostile ...': Learning from an African International Postgraduate Student's Stories of Fear and Isolation within a South African University Campus." Alternation 19(2): 7393.

Ramphele, M., J. S. Crush, and D. McDonald. 1999. Immigration and education: International students at South African Universities and Technikons. Southern Africa Migration project. Cape Town: Idasa.

Rouhani, S. 2007. "Internationalisation of South African higher education in the post-apartheid era." Journal of Studies in International Education 11(3-4): 470-485.

Seekings, J. 2008. "The continuing salience of race: Discrimination and diversity in South Africa." Journal of Contemporary African Studies 26(1): 1-25.

Sehoole, C. T. 2011. "Student mobility and doctoral education in South Africa." Perspectives in Education 29(1): 53-63.

Sennett, J., G. Finchilescu, K. L. Gibson, and R. Strauss. 2003. "Adjustment of Black Students at a Historically White South African University." Educational Psychology 23(1): 107-116. DOI: $10.1080 / 01443410303219$.

Smith, R. A. and N. G. Khawaja. 2011. "A review of the acculturation experiences of international students." International Journal of Intercultural Relations 35(6): 699-713.

Teichler, U. 2004. "Temporary study abroad: The life of ERASMUS students." European Journal of Education 39(4): 395-408.

Tella, O. 2016. "Understanding xenophobia in South Africa: The individual, the state and the international system." Insight on Africa 8(2): 142-158.

Van Manen, M. 2016. Researching Lived Experience - Human Science for an Action Sensitive Pedagogy. New York: Routledge. DOI: https://doi.org/10.4324/9781315421056.

Ward, C., S. Bochner, and A. Furnham. 2001. The psychology of cultural shock. $2^{\text {nd }}$ Edition. Hove: Routledge.

Wilcox, P., S. Winn, and M. Fyvie-Gauld. 2005. "It Was Nothing to Do with the University, It Was Just the People: The Role of Social Support in the First-Year Experience of Higher Education." Studies in Higher Education 30: 707-722. DOI: 10.1080/03075070500340036.

Zhou, Y., D. Jindal-Snape, K. Topping, and J. Todman. 2008. "Theoretical models of culture shock and adaptation in international students in higher education." Studies in Higher Education 33(1): 6375 . 